\title{
A IMPORTÂNCIA DO AMBIENTE FÍSICO ${ }^{1}$
}

\author{
Gary Evans $^{2}$ \\ Universidade de Cornell
}

Este artigo aborda a definição de Psicologia Ambiental segundo os critérios usados para os termos: científico, ambiente físico $e$ comportamento humano. Enfatiza a questão do ambiente físico objetivo, propondo o objeto da Psicologia Ambiental como o estudo científico do relacionamento entre o ambiente físico e o comportamento humano. Finaliza apontando que a pergunta a ser feita é como o contexto sóciocultural afeta o ambiente físico.

Descritores: Psicologia ambiental. Ciência. Ambiente físico. Comportamento.

Galarei a respeito de duas questões: a primeira, sobre o que penso e como 1 defino a Psicologia Ambiental; em que consiste ela; o que estudamos ou devemos estudar; a segunda questão, sobre a qual falarei brevemente, referese ao papel do contexto cultural e social ao considerarmos essa questão.

A primeira destas questões - o que devemos estudar em relação à definição do que vem a ser a Psicologia Ambiental -, consiste em um estudo científico das relações entre o ambiente físico e o comportamento humano. Portanto, isso envolve três aspectos, a meu ver, importantes. $\mathrm{O}$ primeiro se refere ao termo "científico"; o segundo, ao termo "ambiente físico"; e o último, ao "comportamento humano".

1 Transcrição: Kátia de Bonis.

2 Professor da Universidade de Cornell (E.U.A.), responsável pelas áreas de estudos e pesquisas em Projetos e Análises Ambientais e em Desenvolvimento Humano da Universidade de Cornell. Endereço eletrônico: gwe1@ cornell.edu

Psicologia USP, 2005, 16(1/2), 47-52 
Em relação ao estudo científico, um dos aspectos que distingue a Psicologia Ambiental de outras abordagens é que ela está baseada em um modelo científico. Por motivo de tempo, não posso me alongar sobre o significado disso, mas as nossas variáveis tradic ionais devem ser operacionalizadas de modo que outros possam fazer o mesmo experimento referente àquilo que ocorre quanto ao relacionamento entre algumas dessas variáveis. Há algumas regras quanto à evidência: distinguimos entre causalidade e correlação. Isso tem a ver com o formato da pesquisa, e não com a metodologia, uma confusão feita com freqüência. Outro aspecto que a torna científica é a ênfase na mensuração: a maneira pela qual medimos o ambiente físico e o comportamento humano deve ser válido e confiável; porém, por razões de tempo, não poderemos abordar todas essas questões.

Penso ser muito importante que o ambiente físico objetivo faça parte de qualquer pesquisa em Psicologia Ambiental. Os psicólogos, com freqüência, confundem-se a este respeito. É o caso de Kurt Lewin, por exemplo, que considera o ambiente em termos sociais, ou dos psicólogos da área do desenvolvimento, grupo do qual faço parte. Usualmente, quando dizemos 'ambiental', queremos dizer social. Entretanto, para os psicólogos ambie ntais, o ambiente físico objetivo é um aspecto crítico daquilo que estamos estudando.

Quanto ao comportamento humano, cabe lembrar que o comportamento não é apenas auto-relato. Uma grande parte da Psicologia Ambiental é baseada somente em auto-relatos, em questionários, em enquetes. $\mathrm{O}$ comportamento humano inclui reações fisiológicas e emocionais, relacionamentos interpessoais, e também, de modo significativo, o desempenho, a produtividade, a cognição. Portanto, o comportamento é mais abrangente do que o abarcado por questionários e auto-relatos.

Tanto o auto-relato quanto questionários e entrevistas são importantes, aprende-se com eles mas, como qualquer metodologia, têm os seus pontos fortes e fracos. Portanto, é importante que procuremos utilizar, quando possível, metodologias variadas para examinar os mesmos fenômenos relacio- 
nados. O que penso que devemos idealmente fazer é o estudo científico do relacionamento entre o ambiente físico e o comportamento humano.

Falarei um pouco a respeito da razão da qual considero o ambiente objetivo importante. Primeiramente, este não é o mesmo que o ambiente subjetivo. Se olharmos, por exemplo, a correlação entre o ambiente físico e os relatórios dos diferentes indivíduos sobre esse ambiente, a correlação não é muito alta. Portanto, quando medimos o ambiente usando um método subjetivo para representar o ambiente físico, não sabemos qual é o estímulo, não sabemos o que estamos medindo, pois parte do resultado que obtemos é o ambiente físico, e parte são aspectos como a personalidade e as experiências. Não estou dizendo que esses aspectos não sejam importantes, apenas que eles não são a mesma coisa e, às vezes, não temos essa distinção clara. Uma outra razão é que, se você está interessado em saber como o ambiente físico objetivo influencia o ambiente subjetivo, você tem de separá-los para poder estudá-los e, certamente, essa é uma área de estudos muito importante: como o ambiente objetivo afeta nossa percepção. Mas, se você usar a sua percepção como ponto de partida, não conseguirá ver essa relação.

Uma outra razão que justifica a importância de olhar para o ambiente físico em nossos estudos está relacionada ao interesse que se pode ter pelas políticas - muitos de nós, aqui, temos o interesse pelas políticas, bem como pela criação do conhecimento. As pessoas que desenvolvem as políticas normalmente se interessam em regular, proteger ou mudar o ambiente físico. A Agência de Proteção Ambiental Brasileira não mede as percepções que as pessoas têm da poluição do ar, e sim, as partículas do ar, ela regula os elementos químicos e tóxicos do ar. Arquitetos e planejadores urbanos manipulam o ambiente físico. Uma das razões pelas quais temos dificuldades de comunicação com os arquitetos e planejadores urbanos é o fato de nós, psicólogos, estarmos interessados no comportamento humano, e normalmente concentrarmo-nos no aspecto subjetivo, esquecendo-nos de que as pessoas que desenvolvem políticas, com as quais queremos conversar, em seus postos e carreiras e com a sua formação, lidam com o ambiente objetivo. 
Em relação ao comportamento humano, penso que já expliquei o porquê considero importante estudar não somente os auto-relatos: é importante o seu estudo, mas também é importante o estudo de outros aspectos.

Passo agora ao segundo aspecto da questão: como o contexto sóciocultural influencia nossos pontos de vista em relação a isso. Ao pensar sobre essa questão, percebi que há duas maneiras de respondê-la: quando o ambiente afeta o indivíduo, qual o papel desempenhado pelo contexto ao alterar ou mudar o relacionamento?; em outras palavras, como o contexto influe ncia a relação entre o ambiente físico e o comportamento humano. Essa é uma das maneiras de se pensar tal questão. A segunda maneira é: como o contexto sócio-cultural afeta o ambiente? Como ele, na verdade, afeta o ambiente físico?

Direi duas coisas a respeito disso. Se tomarmos o contexto ambiental dessa sala de aula, de que maneira as pessoas reagem considerando-se o seu contexto sócio-cultural? Por exemplo, sou norte-americano, muitos de vocês são brasileiros. Reagimos de maneiras diferentes a esse lugar por causa dessa diferença cultural? Em que medida o fato de estarmos no Brasil tem a ver com a forma como essa sala foi planejada inicialmente - os processos de planejamento pelos quais a sala passou, o formato que ela adquiriu, etc.? Há uma história sócio-cultural relacionada ao fato de estarmos no Brasil que afeta, em parte, a sala onde estamos. Essas são questões diferentes e há maneiras distintas de se analisar e responder a essas questões.

Nós damos excessiva ênfase ao status sócio-cultural na Psicologia Ambiental. Há pouca evidência científica quanto a diferenças culturais em relação à maneira como as pessoas reagem ao ambiente físico, a não ser quanto ao significado e à percepção. Se você considerar o comportamento humano como algo mais do que o significado e a percepção, por exemplo se você considerar a fisiologia, o desempenho de tarefas, a saúde física, as evidências quanto a diferenças alturais são pequenas. As pessoas definem o ambiente de maneiras diferentes e o seu significado, para elas, é diferente. Mas, se você considerar outros tipos de comportamentos, você terá homogeneidade e não heterogeneidade. Estou percebendo que a maioria das pes- 
soas aqui não concorda com isso, mas é por isso mesmo que faço essa afirmação de uma maneira tão assertiva.

Se considerarmos o ambiente ou o contexto social sob este ponto de vista, eu destacaria dois aspectos: primeiramente, pelo fato de sermos psicólogos, tendemos a nos interessar pelas diferenças individuais e esquecemos as diferenças ambientais. Esquecemos o fato de que as 'ecologias' em que estamos são diferentes por causa do status sócio-cultural. Os melhores exemplos que posso dar para ilustrar isso são dois: 1) Um deles é o da pobreza. Há uma inter-relação muito estreita entre o status sócio-econômico e o ambiente no qual você cresce - a moradia, o apinhamento, o barulho, a poluição do ar. Todas essas variáveis, no Brasil e nos Estados Unidos, estão fortemente ligadas ao status sócio-econômico. Portanto, o contexto sócioeconômico influencia o ambiente real que nos rodeia desde que nascemos. 2) Moro numa cidade muito pequena, não conheço os vizinhos, o barulho mais alto que ouço é o de uma vaca. O que quero dizer com isso é que o rural e o urbano são exemplos de um contexto sócio-cultural muito importante que afeta o ambiente no qual vivemos. Ao meu ver, essa maneira de pensar o ambiente sócio-cultural tem, em grande parte, passado desapercebida pela Psicologia Ambiental.

Tentamos aqui levar em consideração principalmente a questão da homogeneidade, de que forma a cultura regula as nossas reações; porém, temos ignorado, em grande parte, a forma pela qual as variáveis sócioculturais afetam o mundo em que vivemos.

Evans, G. (2005). The importance of the physical environment. Psicologia USP, 16(1/2), 47-52.

Abstract: The present article approaches the definition of Environmental
Psychology in light of the criteria used for the terms: scientific, physical
environment and human behavior. It emphasizes the issue of the objective
physical environment, proposing that the object of Environmental
Psychology is the scientific study of the relationship between the physical 
environment and human behavior. It concludes that the question to be asked is how the socio-cultural context affects the physical environment.

Index terms: Environmental psychology. Science. Environment. Behavior.

Evans, G. (2005). L'importance de l'environnement physique. Psicologia USP, 16(1/2), 47-52.

Résumé: Cet article aborde la définition de la Psychologie de l'Environnement selon les critères utilisés pour les termes: scientifique, environnement physique et comportement humain. L'auteur met en relief la question de l'environnement physique objectif, proposant l'objet de la Psychologie de l'Environnement en tant qu'étude scientifique de la relation entre l'environnement physique et le comportement humain. Il termine en relevant que la question à se poser est comment le contexte socioculturel met-il en cause l'environnement physique.

Mots-clés: Psychologie de l'environnement. Science. Environnement physique. Comportement. 